Although it is realised that a precise diganosis can be difficult, parents are emphatic that maximum information should be shared. Vague fears are far more distressing than a frank discussion of possibilities. In attempting to protect parents from diagnoses which they see as too ill defined, incomprehensible, or just too awful, doctors leave parents to the ravages of their imaginations. A leaflet could be issued to concerned professionals listing the generalised questions commonly raised and providing guidelines for specific verbal and written answers. (Written information would be a supplement to, not a substitute for, good face-to-face communication.) A written report, tailored to the child's condition and to parental characteristics, would represent a significant advance in professional-client communication. The proposal is appropriate for parents of both the stillborn and the handicapped, sharing a profound grief. For the latter it is a chronic grief, reinforced by the child's very presence, and it is therefore essential to consider all means of alleviating the pain.

Colin Appleton

London SW2

\section{Dental caries and between-meal snacks}

SIR,-The timely letter from Drs A R P Walker and P E Cleaton-Jones (11 February, p 361) highlights important issues: firstly, the role of between-meal sugary foods in the aetiology of dental caries and, secondly, the confusior. which exists in the interpretation of the available data.

If sugar is extremely cariogenic, as it is, ${ }^{1}$ then its effect is likely to be exerted most when it has the possibility of remaining in the mouth relatively undisturbed. A few sweets regularly consumed slowly several times daily may be more cariogenic than a larger amount of total sugar in foods eaten at normal mealtimes followed by consumption of unsweetened foods and adequate oral hygiene. Nearly three-quarters of a century ago Wallace' observed that cooks and confectioners, who frequently taste the foods they are preparing, as a rule have carious teeth. This is seen currently wherever consumption of cakes and sweet pastries between meals is common." Nevertheless, several human studies"; have shown that the cariogenic challenge from sugar in our foods can be modified by other items of non-cariogenic foods eaten at the same time, some of which are included in the list given by Drs Walker and Cleaton-Jones. Yet they apparently disregard the sequence of distribution of sugary and non-sugary snacks in the diet of the subjects they investigated.

Moreover, the difference in caries experience among children in Johannesburg may be related to a difference in their resistance against dental caries. Although comparative studies have shown clearly that race or heredity is of little significance in the development of dental caries when compared with environmental influences, it is evident that factors such as consumption of unrefined foods, maturation of enamel with age, and fluorides in the diet increase the resistance of teeth against dental caries. The variability of net cariogenic influence dependent on these factors has been discussed elsewhere. ${ }^{6}$ Nevertheless, it does not absolve between-meal sugary foods of their cariogenic potential, which could be of major importance.
The association of such indiscriminate consumption of sugar with dental caries is not due to a mere emotive obsession, as Drs Walker and Cleaton-Jones would have us believe. It is a fact established by centuries of careful observation and decades of patient research. It is the acceptance of this fact which has given an impetus to further research in the quest for factors which can raise the resistance of tooth enamel and oral environment against dental caries. ' The elegant primate studies $^{\star}$ at the Royal College of Surgeons of England are but one testimony to this assertion. Until such work can suggest other safe and certain preventive measures we have, in the dietary control of sugar, an excellent way of combating this most prevalent of all diseases. It should be widely appreciated that it is possible for all children, as some have done even in Britain, to grow up free of dental caries by judiciously controlling the consumption of sugar. It is sad that our attention is being continuously diverted into relatively unproductive lines by the failure of some to accept that, in the fight against dental caries, we have reached a stage when the paramount need is to search for means to limit the local hazards of sugar and to search for a way of persuading people to use sugar sparingly and sensibly.

A K ADATIA

Dental School

University of Bristol

Jenkins, G N, International Dental fournal, 1972,

Jenkins, G N, International Dental fournal, 1972,
22, 350.
Wallace, J S, The Cause and Prevention of Decay in Teeth. London, Churchill, 1900.

Confectionery and the Statistics of Dental Caries. London, Cocoa, Chocolate and Confectionery Alliance, 1974

Rugg-Gunn, A J, et al, British Dental fournal, 1975. 139, 351 .

Breld, T, Hirsch, R S, and Mühlemann, H R, British Dental fournal, 1978, 144, 40.

Disease A K, in Refined Carbohydrate Foods and Academic Press, 1975.

Lehner, T, Fournal of the Royal Society of Medicine, 1978, 71, 161 . 1978, W1, H, et al, British Dental fournal, 1975,
139, 45.

\section{Choice of contraceptive method in teenage girls}

SIR,-The 70 s have seen an increasing availability of contraceptive services for the single teenage girl. The introduction of newer intrauterine contraceptive devices (IUCDs), with more doctors being trained to insert them, has led to a growing tendency to use this method in teenage girls. This is especially favoured in those who are poorly motivated to use other methods effectively or have a history of one or more unwanted pregnancies.

Although there is generally a greater awareness of the need to guard against preg nancy, there is a lesser awareness of the still increasing risk of sexually transmitted infection, especially gonorrhoea. The table shows the changes in contraceptive habits in women attending this clinic with gonorrhoea in 1972 and 1976. There was no significant increase overall in the proportion fitted with IUCDs, but there was a significant increase in their use by those who had repeated gonococcal infection in 1976. Seven of 43 "repeaters" $\left(16.3^{\circ}{ }_{0}\right)$ compared with 17 of 373 girls $\left(4 \cdot 6^{\circ}{ }_{n}\right)$ with single infections had an IUCD $(\%=7 \cdot 7$; $P<0.02)$. Teenage girls were responsible for almost half of all female gonococcal infections and were three times as likely as those aged over 24 to have repeated infection in the same year.

Because the increased risk of pelvic inflammatory disease (PID) in those with IUCDs, especially with gonorrhoea, and the increased risk of treatment failure it is our practice to remove them as soon as the condition is diagnosed. Should PID already have occurred there is a high risk of permanent infertility, knowledge of which in the teenage girl can be a severe handicap and lead to longstanding emotional disorders. When more permanent relationships have been established in future years expensive infertility investigation may be required if the history of gonococcal infection is concealed from the spouse and her doctors.

Teenage girls, therefore, need to be counselled that pregnancy is not the only risk of intercourse. Those who provide contraceptive services need to be aware of the marked overlap in those teenage girls who are at risk from repeated unwanted pregnancy and repeated gonococcal infection and should weigh the potentially increased risk of permanent infertility and its consequences before an IUCD is inserted.

G R KINGHORN

Special Clinic,

Royal Infirmary,

Sheffield

Heart-rate response to standing as a test for autonomic neuropathy

SIR,-Using the technique of routine ECG analysis reported by Dr D J Ewing and others (21 January, p 145) the heart rate response to standing has been examined in nine normal young controls and 11 elderly subjects. It was found that the "30:15 ratio" as described by Dr Ewing and his colleagues was not necessarily the most appropriate measurement to take in all cases, for although in all nine of the young controls (mean age 24 years) the overall pattern of response was normal, in three the ratio was less than 1.03 and thus abnormal. Moreover, in these young controls sinus arrhythmia was noticeably present, as can be seen in the figure, and this can lead to great variations in the $30: 15$ ratio. Thus this is not such a simple definitive screening test, and by alteration in the pattern of breathing it may be possible for the subject to alter the value obtained.

Of the 11 old people living in their own homes (mean age 75 years) none showed postural hypotension, but in all the heart rate

Contraceptive methods in women presenting with gonorrhoea

\begin{tabular}{|c|c|c|c|c|c|c|}
\hline & Total & $\begin{array}{l}\text { Pill } \\
\left({ }^{\prime \prime}, 1\right)\end{array}$ & $\begin{array}{c}\text { IUCD } \\
\left({ }^{\prime \prime}\right)\end{array}$ & $\begin{array}{c}\text { Tubal } \\
\text { ligation } \\
\left({ }^{\circ}(1)\right.\end{array}$ & $\begin{array}{c}\text { Barrier } \\
\text { methods } \\
\text { or none } \\
(\text { (") }\end{array}$ & $\underset{\left(\begin{array}{c}{ }^{\prime} \\
0\end{array}\right)}{\text { Pregnant }}$ \\
\hline $\begin{array}{l}1972 \\
1976\end{array}$ & $\begin{array}{l}239 \\
416\end{array}$ & $\begin{array}{c}85(37 \cdot 1) \\
235(56 \cdot 5)^{*}\end{array}$ & $\begin{array}{l}12(5 \cdot 2) \\
24(5 \cdot 5)\end{array}$ & $\begin{array}{l}14(6 \cdot 1) \\
13(3 \cdot 1)\end{array}$ & $\begin{array}{l}101(45 \cdot 1) \\
126(30 \cdot 3)+\end{array}$ & $\begin{array}{l}17(7 \cdot 4) \\
18(4 \cdot 3)\end{array}$ \\
\hline
\end{tabular}

$* \% 1^{2}=21.4 ; \mathrm{P}<0.001 .+\% 1^{2}=11.8 ; \mathrm{P}<0.001 . \%^{2}$ values given at one degree of freedom using Yates's modification. 


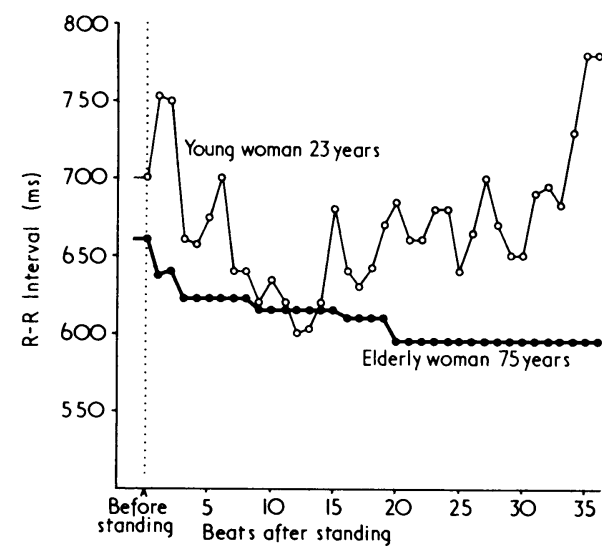

Heart rate response to standing in an elderly subject and a healthy young control.

response to standing was flattened. An example of such a flat response is shown in the figure and the pattern is similar to that found by Dr Ewing and his colleagues in diabetic patients with autonomic neuropathy. The $30: 15$ ratios in these elderly subjects were also low (mean 1.006, $\mathrm{SD} \pm 0.031$; young controls, mean $1 \cdot 107, \mathrm{SD} \pm 0 \cdot 161 ; 0.05<\mathrm{P}<0 \cdot 10)$ and there was no evidence of sinus arrhythmia in 10 of the 11 old people. These findings are in agreement with those of Drs W J MacLennan and A E S Ritch (25 February, p 505), but in the absence of serious disease in the 11 subjects it seems likely that the flattened response can be attributed to aging in the autonomic nervous system. Physiological impairment of autonomic function has been reported in a high proportion of elderly people by Collins et $a l^{1}$ in studies of thermoregulation in old age. ${ }^{1}$

University College Hospital

D J OLIVER Medical School,

London NW 1

'Collins, K J, et al, British Medical fournal, 1977, 1,

\section{Safety in laboratories}

SIR,-We consider, apropos your leading article on this subject (8 April, p 871), that while it is true that laboratory-acquired infections do not seem to be a serious hazard generally in pathology laboratories at present, it may be that with increasing work loads and increasing complexity of methods the situation may deteriorate unless codes of practice such as these mentioned in the article are produced for implementation where possible.

We take the point that processing of "all sputum and other material that may contain tubercle bacilli" in exhaust protective cabinets could cause problems in laboratories. Adequate exhaust cabinets such as are used in properly equipped laboratories should not produce the effect of concentrating an infective hazard. We think that codes of practice are produced to help and guide staff and those involved in laboratory management must be encouraged to employ such codes in a responsible way; in practice, application of these will need to be determined taking into account local circumstances.

Finally, in the last paragraph there is the naive implication that community physicians and environmental health officers are competent to inspect pathology laboratories. We have much pleasant and rewarding experience in collaborating with such staff and respect their expertise but have no doubt that unless they have appropriate laboratory training and experience (uncommon to our knowledge) they cannot be considered competent to inspect such laboratories. Indeed, this paragraph of the article could be quite disastrously counterproductive since, although inappropriate, it could be considered quite seriously by people in some fields of health care, who might in their ignorance attempt to act in error on this advice.

IAN A HARPER

Public Health Laboratory, New Cross Hospital

R G THOMPSON

\section{Antibiotic-associated colitis}

SIR,-Mr T T Irvin's comments (22 April, p 1051) on our paper on pseudomembranous colitis (18 March, p 675) are pertinent although not entirely practical.

We have certainly considered the possibility that the high incidence of pseudomembranous colitis is related to the large number of prophylactic antibiotics prescribed. Indeed, we think this is a major factor. In other surgical units in the same hospital, where prophylactic antibiotics are also used routinely, pseudomembranous colitis appears to be a rare event. It is only on our unit, where we undertake many clinical trials of antibiotic therapy, that pseudomembranous colitis has become so common. Naturally, therefore, we are fully aware of the possible role of multiple antibiotic administration. Nevertheless, we do not accept the statement that abdominal wound infection is rarely a life-threatening problem. In patients undergoing major colorectal surgery not protected by any form of antibiotic prophylaxis the incidence of intraabdominal infection is $10 \%$ and of septicaemia $12 \% 1$; both are life-threatening and lifeclaiming complications that can be prevented be appropriate prophylaxis. Surely it is not the time to put the clock back and abandon prophylaxis but to learn about the causes of complications of prophylactic antibiotic therapy and how to prevent them.

\section{J Alexander-Williams M R B KEIGHLEY}

General Hospital

Birmingham

Washington, J A, et al, Annals of Surgery, 1974, 180, 567.

\section{Management of severe acute asthma}

SIR,-Your leading article (8 April, p 873) on treatment of severe acute asthma does not mention the use of subcutaneous terbutaline. The subcutaneous route of administration is a useful acquisition to the list of present treatments.

There are occasions in general practice, and even in peripheral hospitals that are shortstaffed, when intravenous therapy is not convenient. In addition, older patients and those with associated cardiovascular problems may not tolerate intravenous infusions, with the added fluid load. The other large group of patients who would benefit from a subcutaneous injection are children, in whom it can often be extremely difficult to find a suitable vein

As the subcutaneous route of terbutaline has been shown to be effective ${ }^{1-4}$ I think it should be added to any list of asthmatic management.

J A Hughes

The General Hospital

Jersey, C1

Arner, B et al, Acta Medica Scandinavica, 1970 , Suppl 512, p 25. Suppl 512, p 25 .

Suppl 5 et al, Acta Medica Scandinavica, 1970 Holton, $\mathrm{K}$, British

Holton, K, British fournal of Diseases of the Chest,
$1974,68,111$.
Freedman, B J, British Medical fournal, 1971, 1, 633.

SIR,-I have delayed writing as I was sure that someone of greater authority would take up the cudgels for subcutaneous adrenaline, whose use you condemn in such a cavalier and unreferenced fashion in your leading article (8 April, p 873). One presumes that you are writing as a physician treating adults in hospital, and no doubt the main place for this drug is in children at home, though I would hold (and am supported by authorities such as Hutchison ${ }^{1}$ and Harris ${ }^{2}$ ) that it still remains an effective first-line drug for the hospital management of the young acute asthmatic. Its disadvantages, of poor absorption in the presence of peripheral collapse and cardiac stimulation, are widely known and its advantages, of reliability, safety, and ease of use in even a young child with inaccessible veins, are long tried and tested; the suggestion that alpha-receptors may be more stimulated by adrenaline than beta-receptors owing to betaadrenergic blockade: ${ }^{3}$ is unsubstantiated in practice. The only alternative subcutaneous bronchodilator, terbutaline, has never been compared with adrenaline and experience of its use is limited.

Sir, it ill becomes you to condemn longestablished drugs without even the benefit of argument.

TONY Waterston

Department of Child Health

wells Hospital,

Hutchison, J H, Practical Paediatric Problems, 4th edn. London, Lloyd-Luke, 1975.

${ }^{2}$ Harris, F, British Medical fournal, 1975, 4, 288.

\section{Contraceptive steroids and breast cancer}

SIR,-Mr J D Spencer and others, discussing this relationship (22 April, p 1024), report that the recurrence rate in 44 stage 2 breast cancer patients who had taken contraceptive steroids during the year before mastectomy was significantly lower than in a matched control series. Although the numbers and length of follow-up were limited, the observations suggest that the growth of recurrence may have been temporarily inhibited in some cases as a result of the patient taking a combined pill of progestin and oestrogen.

It is a pity that the authors failed to mention evidence of this, which was reported over 10 years ago. ${ }^{1}$ Soft-tissue manifestations of recurrent and advanced breast cancer in 42 women were treated with Lyndiol, an oral contraceptive containing a synthetic progestin of the 19-nor-steroid group associated with the oestrogen mestranol. After the contraceptive dose of one tablet daily for two months or longer almost complete regression of softtissue tumour was noted in 4 of 21 cases; with a dosage of 4-6 tablets daily it was noted in 5 of 21 other cases. The response rate and its mean duration were found to be almost identical with those noted in a series of 72 